TEYPERATURE AND HUMIDITY REGULATORS.

The automatic regulation of the temperature of an apartment heated by water, steam, gas or air may render very great services not only in industrial, but in domestic heating, as, for example, in the keeping of the temperature of a parlor, hospital ward, etc., constant. Such a result is obtained by means of the apparatus represented diagrammatically in the accompanying figure, and constructed by M. Dorian. It consists of a metal receptacle, $A$, mounted on a suitable board and terminating at its lower end in a diaphragm chamber, $D$. A passage connects the bottom of this chamber with a rubber pipe, $B$, which is inclosed within a coiled spring. The spring in turn is inclosed in a stout supporting tube (shaded black in the figure), in the bottom of which fits a movable plunger that branches out and carries a large outer spring, $\boldsymbol{R}$. This spring forces the rubber tuive back to its original length, after the expansive fluid within it has ceased to act.

The receptacle, $A$, contains amylic alcohol, the rubber tube is filled with mercury, and the two fluids are separated from each other by the diaphragm, $D$. A valve-box, $P$, completes the system, and serves for the setting of the apparatus by regulating the pressure, which varies from 3 to 8 kilogrammes per square centimeter, according to the use for which it is designed. The operation of the regulator is as follows: Under the influence of the variations in temperature acting upon the receptacle, $A$, the tube, $B$, elongates or contracts, and, if its free extremity is connected with the key of a stop cock, it will be able to open or close the passage through which flows the fluid designed for heating.

Although the spring, $R$, seems useless, it nevertheless plays a special rôle, which we shall explain by seeking to estimate the force that the apparatus is capable of exerting.

Let us take a regulator and dispense with the spring $R$. During the expansion of the liquid in the receptacle, $A$, the rubber tube will elongate, and then, if it meets with a resistance (produced, for example, by the closing of a cock), it will be arrested. Now, as the receptacle continues to absorb heat units, the internal pressure will rise until its value is sufficient to overcome the obstacle. If the liquid contracts, the tube will shorten under the action of the atmospheric pressure

Thus, if the obstacle to be overcome requires a force of 5 kilogrammes and if the section of the rubber tube i. one square centimeter, the internal pressure will rise to 6.033 kilogrammes (5 kilogrammes + the atmospheric pressure) in order to overcome the resistance. During the contraction, the force will be but 1.033 kilogrammes and consequently inadequate.

1.033 kilogrammes and consequently inadequate.
The object of the spring, $R$, therefore, is to increase The object of the spring, $R$, therefore, is to increase the power of the apparatus at the moment of the contraction. During the expansion, the stress produced may be greater than the resistance to be overcome, and, in this case, the spring may store up the excess of energy in order to restore it in the inverse motion. During the expansion, the effective force produced is equal to the internal pressure less the contrary pressure of the spring, $R$, added to the atmospheric pressure

During the contraction, the effective force is equal to the atmospheric pressure increased by the action exerted by the spring. This explanation shows that the power of the apparatus depends upon the section of the tube and the internal static pressure, and that the play of the tube depends upon the volume of the liquid and its coeficient of expansion. Upon causing all these factors to vary, it is possible to obtain the results desired

In the ap-
paratus as at paratus as at
present constructed th receptacle, $A$ has the form of a round or of a round or half-flat spiral of the figure) so that the sur face influenced by heat may be increased. The sensitiveness of the apparatus is equal to that of a laboratory the r mo meter. The forms we illustrate, type $C$ and $E$, are arranged f or heating by illuminating gas. $\mathrm{Nu}$ uerous application have been

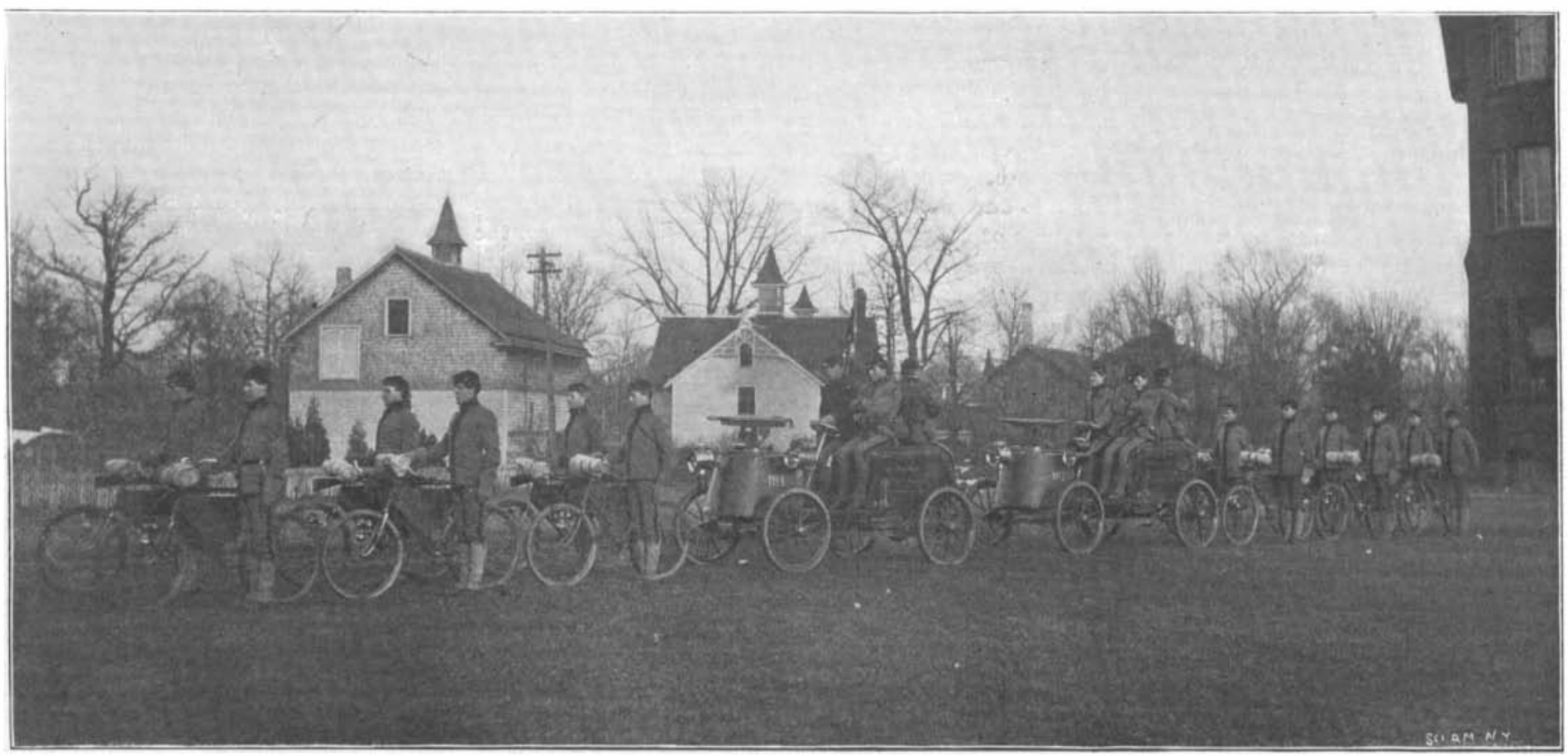

THE AUTOMOBILE FOR MILITARY INSTRUCTION. by combustion being inadequate. lighting and extinction of the stove can be effected in an instant; and, since the flame is visible, it makes the room heated appear as cheerful as does a wood fire in a fireplace.

The odor that is often complained of when heating is done by gas is always due to defective installation, the means of egress from the room of the gas produced

The example of the heating of a clinical room is mentioned designedly in order to show that a perfect installation has no bad action upon the health, even upon that of delicate infants unides, the consumption of gas is considerably diminished by the use of the temperature regulator under consideration.

The same good results are obtained in industrial heating.

The mention of a single application will suffice to show the capabilities of this apparatus. In certain industries, such as the textile ones, it must be possible to regulate the degree of humidity of the air, in order to obtain proper results in the manufacture. Such regulation is effected by hand. The Société Industrielle de Mulhouse, struck by the inconveniences of this method of procedure, opened a competition for an apparatus that should permit of an automatic regulation. As the apparatus described in this article is in reality merely a thermometer with dilatable rod, the manufacturer conceived the idea of employing it as a psychrometer by using two regulators, one with a dry receptacle acting upon the heating and the other with a receptacle surrounded by canvas kept constantly moist and acting upon the conduit of humidification. A regulating psychrometer of this type was installed at the establishment of Scheurer Lauth \& Co., at Thaun, during the month of July, 1899, in a drying house of 1,000 cubic meters capacity. The results obtained were perfect. The dry and moist temperature did not vary more than half a degree; and, as such variation occurred in the same direction with both regulators, the result was that the percentage of humidity remained constant at about one per cent. Other apparatus also are arranged for giving a constant percentage of humidity, whatever be the temperature of the room.-Translated for the Scientific AMERICAN from La Nature.

\section{THE WAR AUTOMOBILE}

BY DAY ALLAN WILL

The use of the automobile in connection with military service for mounting light artillery in this country originated with Major R. P. Davidson, commandant at the Northwestern Military Academy of Highland Park, Ill. Major Davidson has been experimenting with motor vehicles for several years, in making forced marches, long-distance tours, and in what might be called light artillery evolutions. Twice he has essayed to make a record trip from Chicago to Washington with an automobile carrying a gun crew of four men and a rapidfire gun. Owing to the wretched condition of the highways, which was further aggravated by rainy weather, each time the trip has been abandoned when partly completed.

This year, the cadet corps of the academy has been organized to include a bicycle and automobile gun attachment, which is probably the only military organization of its kind in the world. The gun battery consists of two Colt automatic rapid-fire pieces of 7 millimeters caliber, each firing 480 shots per minute. They are constructed to utilize smokeless powder, and each is equipped with a bullet shield to protect the operator when in action. Each gun is manned by a sergeant ator when in action. Each gun is manned by a sergeant vehicles are operated by 10 horse power engines utiliz in $g$ gasoline, giving a speed of 25 miles an hour on the ordinary country pike. The carriages have reservoirs with a capacity for 22 gallons of gasoline, a n a $\mathrm{r}$ e equipped with acetylene $1 \mathrm{amps}$ for night service. The front portion of the motor contains a foundation of $\mathrm{sh}$ eet $\mathrm{steel}$ upon which the gun is mounted. The general design of the carriage was conceived by Major Davidsonor Dasult of experi- 
ments he has been making. The gun squad accompanies the bicycle infantry illustrated in the accompanying photograph, in marches through northern Illinois; and to test the ability of the vehicles crosscountry, trips are frequently taken through cultivated fields and underbrush, the idea being to test the efficacy of the carriages as a substitute for horses in artillery service. The single-motor carriage depicted is the first motor which was tested by Major Davidson and was utilized in the attempted run between Chicago and Washington. It might be said that the same obstacle which resulted in the failure of Mr. Alexander Winthe Pacific to the Atlantic coast, caused the failure of Major Davidson's attempt - the sandy condition of the highways.

\section{THE RAPID TRANSIT SUBWAY, NEW YORK.}

The construction of the great twenty-one mile system of underground railway known as the New York Rapid Transit Subway would be a notable feat of engineering, even if it were being built under what might be called normal conditions of traffic, such as may be found in the outlying and less thickly populated suburbs; but as a matter of fact, the difficulties of the work have been enormously increased by the condition that practically the whole of the tunnel lies immediately beneath the double tracks of the bustracks of the busiest street surface trolley lines
in the city. in the city.
These tracks being of the underground - trolley type a re extremely heavy in construction, in construction, while most of
the cars which traverse them $\mathrm{a} r$ ef $\mathrm{th} \mathrm{e}$ $\mathrm{l} \mathrm{a} \mathrm{r} \mathrm{ge} \mathrm{s} \mathrm{t} \mathrm{and}$ heaviest ty pe, and run under an unusually close headway, it being it being no un common thing for three or four cars to be on
one block at the $\mathrm{s} a \mathrm{me} \mathrm{tim}$. Moreover, $\mathrm{th}$ e subway lies, as we have said, for the greater part the greater part of its length beneath some of the principal ar teries of vehicular traffic in the city, and it was laid down as one of the strict conditions i mposed upon the contractors, that there must be no interference whatever with the operation of the electric tracks, and the

least possible obstruction to ordinary street traffic. The problem of carrying the electric tracks while the solid ground beneath them was being cut away was no ordinary one, and considerable ingenuity has been shown in working it out. On the front page of this issue will be found a cross section taken on Fourth Avenue, show ing the means adopted for supporting the trolley tracks and also the great number of gas, water an electric mains, while the earth and rock were being excavated, the steel framing built in place, and the concrete covering and the back filling and surface filling put in.

The method of carrying the electric tracks was as follows: At the level of the street surface two pairs of 24-inch I-beams, 2 feet in depth and about 35 feet in length, were placed parallel with the tracks, one pair on each side thereof. At each end of the I-beams $12 \times 12$ posts were sunk to a firm foundation, and for the length of track covered by the I-beams the soil beneath the yokes carrying the tracks was dug out, and $12 \times 12$ timbers placed underneath them crosswise to the track. Heavy bolts were then passed up from the ends of the transverse timbers to the top flanges of the I-beams and drawn up snugly by nuts, the load of this I-beams and drawn up snugly by nuts, the load of this
stretch of track with the cars upon it being thuc transferred to the I-beams. Similarly, $12 \times 12$ support- ing timbers were placed from the I-beams to the adjoining sidewalks on either side, one end being boited to the I-beams and the other resting upon the sidewalk flagging. The material was then excavated by pick and shovel, dumped into buckets of an overhead cableway, loaded into carts and taken to some convenient dumping ground. The timbers extending from the I-beams to the sidewalks served to hold in place and carry during the progress of excavation the numerous water, gas and electric mains, which lie immediately below the surface of the street. These were slung from the beams by stout chains, which held them securely in the ing. As the excavation was carried down, additiona and longer $12 \times 12$ posts were put in place until subgrade was reached. The foundation blocks and concrete floor were laid and the steel columns and the I-beams of the roof erected, the side walls and the intervening arches of concrete built in place, and the back filling rammed in, completing the work. As the filling was brought up to grade, the chains supporting the gas and water mains were unslung and the $12 \times 12$ timbe water mans were unst moved, the surface of the street being finally restored to its original condition. The steel framing is spaced about 5 feet apart longitudinally and answers in some sense to

have been repaved and put in first-class condition. From the south side of Astor Piace to Ninth Street no excavation has been done, there being some dispute with the owners of the buildings underrieath which the tunnel at this point will have to pass. From Ninth Street the excavation is complete, the steel work is in and most of the concreting completed to Fourteenth Street, where more than half of the excavation for the large Fourteenth Street station has been done and the balance of the work is being pushed forward with great dispatch. From Fourteenth Street to Seventeenth Street the solid rock has been excavated for three of the four tracks, the steel has been put in, and the street restored to its original condition. Most of the excavation has been done for the Eighteenth Street station, and for the block immediately to the north of it. From Nineteenth Street to Twenty-third Street the work is nearly finished, as is the excavation for the Twenty-third Street station, which is about ready for the insertion of the steel framework. From Twenty-third Street to Thirty-third Street there is a practically unbroken stretch of completed Subway. The excavation is still going on for the Thirtythird Street station, and at the portal of the twotrack tunnels which extend from Thirty-third Street to Forty-second Street. On both the east and w e s t s i d e branches of the tunnel on this tunnel on this tion is com. p l e t e d, a nd about half of the concrete lining has been put in piace.

There is a gap of about one b l o c k opposite Vanderbilt Ave nue on Forty. second $\mathrm{Street}$ most of it solid rock work, úpon which no work of excavation has been done; but from just west of Vanderbilt Avenue to Broadway the stretch of line through Fortysecond Street is about $\mathrm{th} \mathrm{h}$. e equarters excavated, and lated, and a large amount of the steel work is in place and concreted u p. $\mathrm{There}$ is another gap at Forty - second Street and B r o a d w a y, where work is be ing delayed by a dispute with the property ow n e r s,
and but little work has been done as yet at

the framing ribs of a modern steamship. The concreting between the side posts and between the I-beams of the roof is built in arched form to enable it better to re sist the crushing pressure to which it is subjected.

The accompanying plan showing the progress of the work to date will be of considerable interest. On those portions of the road covered by heavy black lines, the work of excavation has been completed, while the in tervening gaps represent the work that has been only partially excavated. Commencing at the loop under City Hall Park, we find that the excavation has been entirely completed, and, indeed, very little remains to be taken out if we except the large station at the Brooklyn Bridge, as far north as Pearl Street. From Pearl Street to just below Canal Street but little work has been done. It was anticipated that on account of this ground having originally been a swamp, there would be considerable trouble with water, for which reason this particular stretch of line was left until the last The contractors, however, are not experiencing ot experiencing any abnormal difficulty, and it is likely that the intervening gap of a few blocks will be completed by the fall of next year. From Canal Street to Astor Place the Subway has been entirely excavated, practicall the whole of the steel work and concreting is done, anc before many months the surface of Elm Street will
Long Acre Square. From Forty-fifth Street to Seventysecond Street there is the longest stretch of completed line on the whole system. With a few exception: this work is not only excavated, but the steel is in and concreted up and the street surface is largely restored. From Seventy-second Street to Eighty-first Street the work is somewhat backward. In places the ground is scarcely broken and there is here much work yet to be done. From Eighty-first Street to 100th Street, excavation is completed and much steel in place. There is considerable work to be done for two blocks south of 104th Street, where the four-track road divides into its western and eastern branches. From 104th Street to 110 th Street on the west branch, the excavation is completed in stretches, while there are one or two blocks on which much work remains to be done. From 110th Street to Manhattan Valley excavation is practically completed, while about three quarters of the elevated structure across the Valley has been erected, and only awaits the delivery of the 160 -foot steel arch over Manhattan Street to enable this fine viaduct to be completed. At present the structure is painted red, but ultimately, when it has been given its coating of olive green, it will present a thoroughly attractive appearance. The design of the bridge is more open and less cumbersome than the adjoining Riverside viaduct, 